Journal of Research in Interprofessional

Practice and

Education

Vol. 1.2

August, 2010

\title{
How Medical Students Conceptualize Health and Disability: Implications for Interprofessional Practice and Education ${ }^{1}$
}

\author{
Daniel J. Bechard, MSc; Adam M.B. Day, MSc; \\ Sinéad Dufour, MSc. (PT); Agnieszka Dzioba, MSc; Colin McCabe, MSc; \\ Scott M. Rasmussen, MSc; Philip C. Doyle, PhD
}

\begin{abstract}
Background: This study explored whether medical students at a Canadian university conceptualize health and disability from a biomedical or biopsychosocial perspective. The World Health Organization's (WHO) International Classification of Functioning, Disability and Health (ICF) served as the theoretical basis for this exploration.

Methods: A written survey was administered to capture medical students' conceptualizations of health and disability. The survey included questions explicitly related to the constructs of universalism, nonlinearity, social and environmental factors, personal factors, participation, aspects of language and biopsychosocial health perspectives. The survey was also designed to include both theoretical and scenario-based questions related to biopsychosocial concepts of disability. The survey was distributed to and completed by a senior medical school class at a Canadian university.

Results: In total, 82 out of 131 medical students completed the survey. Observed trends suggested that for theory-based questions, respondents exhibited close agreement with biopsychosocial perspectives of health and disability. Scenariobased questions resulted in more variability among respondents compared to theory-based questions. When students who previously had been introduced to the ICF were compared with students who had not, those familiar with the ICF more consistently exhibited a biopsychosocial perspective of health and disability; however these differences were not statistically significant.

Conclusion: Overall, senior medical students in this study were generally found to conceptualize disability using a biopsychosocial orientation. This result was more pronounced among students who were previously familiar with the ICF. Interestingly, a biopsychosocial orientation was not consistently maintained for scenario-based questions for all respondents. Our current healthcare climate requires that the concept of health move beyond a biomedical perspective to a more holistic biopsychosocial perspective. This change in perspective is of particular importance as movement towards team-based models of care continues to gain momentum. Closing conceptual and language-based gaps related to concepts of health and disability among all healthcare professionals is pertinent to improving interprofessional collaboration and service provision. The ICF presents a framework and language that is relevant across all health professions. Increased use of the ICF in health professional education and training could significantly contribute to increased interdisciplinary success.
\end{abstract}

Keywords: Disability; Health; ICF; Interprofessional collaboration; Medical education

Journal of Research in Interprofessional Practice and Education (JRIPE)

Vol. 1.2

(c) 2010

Corresponding author:

Adam Day

ı_day4@@uwo.cai 
160

How Medical Students Conceptualize Health and Disability

Bechard, Day, Dufour, Dzioba, McCabe, Rasmussen, \& Doyle

Journal of Research in Interprofessional Practice and Education

Vol. 1.2

August, 2010

\section{BACKGROUND}

Health: An evolving concept

Views regarding the conceptualization of health have changed over time and will do so as long as health-related needs and expectations continue to evolve. The biomedical model traditionally used within healthcare-one that focuses on the physical processes of diseases and impairment-no longer adequately captures the multidimensional nature of health that has been increasingly acknowledged in the literature [1-4]. The contemporary description of health and disability is best articulated by the International Classification of Functioning Disability and Health (ICF), which was developed by the WHO in 2001 and evolved from iterative revisions of the International Classification of Impairments, Disabilities and Handicaps [3,4]. The ICF is grounded in a biopsychosocial approach to health, meaning that biological, psychological, and social factors are all recognized to influence health $[3,5,6]$. The ICF is the conceptual basis for the definition, measurement and policy formulation for health in the $21^{\text {st }}$ century [4].

Core elements of the ICF framework are organized into two parts. Part one, termed functioning and disability, contains three components: 1) body functions and structures, 2) activity, and 3) participation. In the ICF, body functions and structures describe the anatomic and physiologic parts and functions of the body; activity describes the ability to perform a certain task; and participation represents involvement in a meaningful life situation. Furthermore, when deficits in health or functioning do exist, each of these components may be expressed negatively as impairments, activity limitations and/or participation restrictions. In the ICF, disability serves as an umbrella term to either individually describe the presence of a specific impairment, activity limitation or participation restriction, or any combination of the three [4].

Additionally, part two of the ICF, termed contextual factors, describes not only how disability impacts one's life, or what influences one's experience of disability, but also the impact of one's relationships with the world in which he or she lives. Contextual factors are separated into two components: environmental factors and personal factors. Environmental factors describe the built environment and sociocultural climate in which one lives and capture how one experiences disability, inclusive of one's relationships with friends and family, the home, and the workplace. The personal factors component describes features that are specific to one individual (e.g., age, gender, socio-economic status, lifestyle choices, coping styles, past experiences, etc). Although it is acknowledged that such personal factors are important in the manifestation of health, the current iteration of the ICF does not code for personal factors because they are not explicitly part of a health condition or health state [4]. As shown in Figure 1, the ICF is structured as an integrated framework with its various components connected via bidirectional arrows. These arrows represent both the independence of each component and the interdependence of all of the components, as well as the contextual nature in which health exists.

Since it's adoption by the WHO in 2001, the ICF has been embraced and advocated as an advanced framework for conducting health-related research and clini- 
161

How Medical Students Conceptualize Health and Disability

Bechard, Day, Dufour, Dzioba, McCabe, Rasmussen, \& Doyle
Journal of Research in Interprofessional Practice and Education cal practice in the fields of nursing [7,8], occupational therapy [9], physical therapy [10], speech-language pathology [11-13], oncology rehabilitation [14], and stroke rehabilitation $[15,16]$ among others. Similarly, the ICF has been advocated for use in a growing number of clinical populations [17-25]. As well, the ICF has officially been included in the scope of practices of the American Speech Language Hearing Association [26,27], American Physical Therapy Association [28], and it has been recommended for conducting meaningful outcomes research [17] and evidencebased medicine [29]. Further, in its 2007 review of disability in America, the Institute of Medicine [30] has officially adopted the ICF framework as its conceptual model of disability, and the Canadian Institute of Health Information has adopted the ICF as its coding and classification standard [31].

As the ICF continues to proliferate in research and professional practice, the benefits of a common conceptual framework and standard language relative to fostering interdisciplinary collaboration among healthcare providers is being realized. For example, in discussing interdisciplinary rehabilitation, Mueller et al. [32] have described the ICF framework as the potential "missing link in this communication process" (p.1). The ICF's potential to foster effective interdisciplinary communication has been noted by others as well $[7,8,16]$. Further, in describing their experiences with the ICF in stroke rehabilitation, Tempest and McIntyre [16] have noted the ICF framework's utility extends beyond facilitating communication by helping to clarify member roles in multidisciplinary teams. Indeed, as clinical settings and practices continue to evolve toward collaborative care teams, adoption, and knowledge of the ICF will be fundamental to team efficiency and efficacy $[33,34]$.

Figure 1

\section{The ICF model: A non-linear approach to health and disability (Reprinted with permission).}

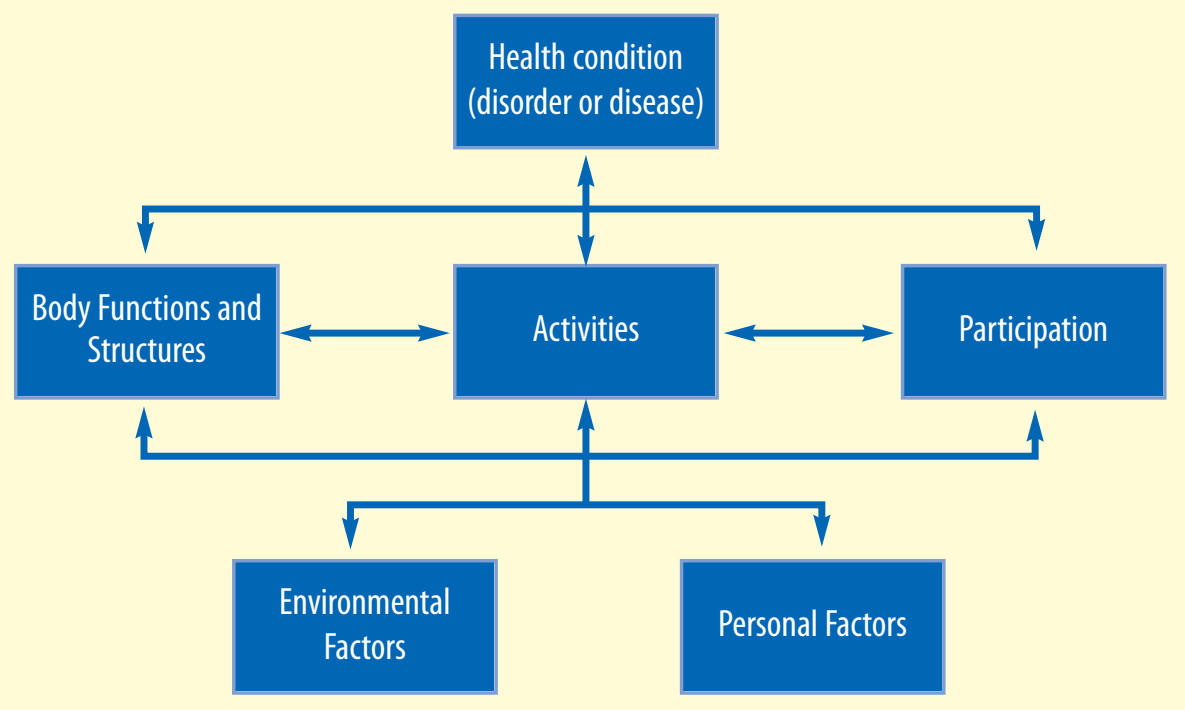


162

How Medical Students Conceptualize Health and Disability

Bechard, Day, Dufour, Dzioba, McCabe, Rasmussen, \& Doyle

Journal of Research in Interprofessional Practice and Education

Vol. 1.2

August, 2010

\section{Perceptions of health}

Individuals and professional disciplines alike are accompanied by varying assumptions and values [35-38]. With the progression towards interprofessional models of service provision, teams of providers will include individuals from various professional disciplines. As such, members of the team will undoubtedly formulate healthcare problems from differing perspectives and use different evidence bases in order to address the problems experienced or perceived by the team [6,33]. Therefore, the need to shift distinct professional paradigms toward a universally-shared framework to guide clinical decision-making is evident and necessary, and the ICF can serve this need. Specifically, the ICF offers a unified conceptual framework and standard, common language that serves to facilitate knowledge generation and transfer across disciplines, as well as language and cultural borders $[1,39,40]$.

\section{Interprofessional practice and education}

Effective teamwork is now seen as a key solution to enhancing the provision of health and related services $[38,41-46]$. In healthcare settings, individuals from different professions come together to care for patients. These groupings of people are sometimes assumed to form a healthcare team; however, a group of people who happen to work together are not truly a team unless specific conditions are present and met $[41,43,44,47,48]$. Inherent in the notion of teamwork is the concept of true collaboration, meaning cooperatively working together, sharing responsibility for solving problems, and making decisions to formulate and carry out plans for patient care [49].

Although consensus exists that effective teamwork can translate to higher quality healthcare services, the method to transform a group of individuals into an effective healthcare team continues to present challenges. There are many identified barriers to effective teamwork in healthcare settings, including different cultures (both socially and professionally) and languages that exist across different disciplines $[6,36,38,50]$. A team is a multidimensional construct, and team structures and processes can vary widely according to membership, scope of work, and interactions [48]. The conceptual confusion that is present with multiple participants is a significant barrier to achieving effective interprofessional practice [51]. As such, there is a call for changing the way health professionals are educated so that they will have the knowledge, skills, and attitudes to carry out collaborative, interprofessional patient-centred practice $[52,53]$.

In an effort to improve the efficacy and efficiency of interdisciplinary healthcare teams, Health Canada has recently focused on improving interprofessional education which involves: 1) socializing healthcare providers to work together in sharing problem solving and decision making, 2) developing mutual understanding and respect for the contribution of various players, and 3) instilling the requisite competencies for effective provision of service $[38,53,54]$. The way we educate health providers is fundamental to achieving system change and to ensuring that health providers have the necessary knowledge and training to work effectively on interprofessional teams within the evolving healthcare system. 
163

How Medical Students Conceptualize Health and Disability

Bechard, Day, Dufour, Dzioba, McCabe, Rasmussen, \& Doyle
Journal of Research in Interprofessional Practice and Education

Vol. 1.2

August, 2010
While achieving improved interdisciplinary collaboration among veteran healthcare professionals may be more challenging given the degree to which one may be "locked" to a given discipline and its tenets, students and junior professionals can be directly targeted and educated in collaborative practice. Fundamental to such education is the adoption of universal terms and constructs. For example, similar to how anatomic structures, planes, and directions evoke collective understanding among nearly all healthcare professionals, the ICF provides a systematic framework to conceptualize health and disability, and a standard language for its description. It is important to note, however, that universal adoption of the ICF does not preclude the potential for discipline-specific specialization and innovation; instead, a common language and framework will facilitate the translation and transfer of knowledge that might otherwise be "buried" by esoteric layers of discipline specialization. Therefore, we believe that healthcare professionals should, at minimum, be introduced to the ICF's conceptual framework and language. Even a basic introduction to the model and its fundamental principles may help to bridge gaps that could lead to inefficient interdisciplinary care teams. Like many before us, we support the view that the ICF conceptualizes health and disability from a perspective that is congruent with contemporary health-related needs and expectations across health disciplines $[1,3,4,30,33]$.

\section{Purpose}

Despite the increasing adoption of the ICF framework worldwide, and despite medicine being the largest health discipline, there is a paucity of literature regarding the potential utility and application of this conceptual framework for health and disability in medicine (the IOM's recent support for the ICF framework notwithstanding). Given the current move toward interprofessional models of practice, barriers related to differing perspectives of health among various disciplines, and the important role of education to strengthen the practice of interprofessional teams are critical. Thus, medical students' perceptions of health and disability may be viewed as an important contributor to the collaborative provision of health services. Consequently, the purpose of this study was to explore how medical students at a Canadian university conceptualize health and disability. Specifically, we sought to explore how language and context were interpreted in these students' conceptualizations of disability, and whether their conceptualizations were oriented from a biomedical or biopsychosocial perspective, relative to the foundations of the ICF.

\section{METHODS}

Participants

Participants in this study were 131 senior medical students (72 females and 59 males) from a single accredited Canadian medical school. Senior medical students were chosen because they were more than halfway through their degree program, and were therefore likely to have developed their own perceptions of the nature of health and disability. Of the 131 students for whom questionnaires were distributed, 82 (50 females, 27 males, and 5 individuals who did not specify gender) were 
164

How Medical Students Conceptualize Health and Disability

Bechard, Day, Dufour, Dzioba, McCabe, Rasmussen, \& Doyle
Journal of Research in Interprofessional Practice and Education

Vol. 1.2

August, 2010
Table 1

\section{Demographic variables $(n=82)$}

\begin{tabular}{lc} 
Sex & \\
Females & $50(61 \%)$ \\
Males & $27(33 \%)$ \\
Unidentified & $5(6 \%)$ \\
\hline Mean Age (range) & $24.92(23-30)$
\end{tabular}

\begin{tabular}{lc} 
UUndergraduate Degree & 55 \\
BSC & 15 \\
BHSc/Life Sciences & 5 \\
BKin & 4 \\
BA & 1 \\
BEng & 2 \\
Other/NA & 3 \\
\hline Master's Degree & 67 Yes (82\%) \\
& 15 No (18\%) \\
\hline Previous Knowledge or Introduction to ICF* F First Language & 40 Yes (49\%) \\
& 41 No (50\%)
\end{tabular}

Note: * Data may not add to 82 where data was missing

\section{Survey development}

A thorough literature search did not yield any measurement instruments that assessed perceptions of contemporary perspectives of health and disability; therefore, we developed a survey in an effort to capture how disability is conceptualized. When designing the survey, we decided that it should have its foundational grounding in the theoretical framework of the ICF; however, items contained in the survey were designed to capture one's conceptualization of disability relative to each of the underlying constructs, not defini-

\section{Table 2}

\section{ICF constructs and definitions included in the survey}

\begin{tabular}{|c|c|}
\hline ICF Construct or Concept & Definition \\
\hline Universalism & $\begin{array}{l}\text { The ICF is applicable to all people, across geographic and cultural borders, and is not static, but dynamic } \\
\text { throughout the lifespan. }\end{array}$ \\
\hline Nonlinearity & $\begin{array}{l}\text { The ICF does not predict a particular outcome, such as disability, but rather acknowledges that each } \\
\text { component may exist independently, as well as influence other components, and that one's experience is not } \\
\text { locked in time. }\end{array}$ \\
\hline Environmental factors & $\begin{array}{l}\text { One's experience of health and disability is a function of how one interacts with the environment in which } \\
\text { they live, including the built environment, as well as the sociocultural and political climate. }\end{array}$ \\
\hline Personal factors & $\begin{array}{l}\text { The acknowledgement that any number of personal attributes, beliefs, experiences, or one's socioeconomic } \\
\text { status will influence one's experience of health and disability. }\end{array}$ \\
\hline Participation & Refers to one's ability to engage in activities, tasks, or social situations that are considered meaningful. \\
\hline Neutral language & $\begin{array}{l}\text { Language in the ICF is free from underlying assumptions of one's performance or capabilities, is not intended } \\
\text { to predict an outcome or progression of health or disability, and is free from connoting social penalty, } \\
\text { prejudice, and stigma. }\end{array}$ \\
\hline $\begin{array}{l}\text { Biopsychosocial } \\
\text { health perspective }\end{array}$ & $\begin{array}{l}\text { An acknowledgement of the role of physical, psychological, and social factors in contributing to one's } \\
\text { experience of health and disability. }\end{array}$ \\
\hline
\end{tabular}


165

How Medical Students Conceptualize Health and Disability

Bechard, Day, Dufour, Dzioba, McCabe, Rasmussen, \& Doyle
Journal of Research in Interprofessional Practice and Education

Vol. 1.2

August, 2010 tional material of the ICF. The authors held open group discussions to determine which concepts and constructs were deemed to be imperative for an inclusive and biopsychosocially oriented perspective of disability. A list of included ICF constructs and their definitions can be found in Table 2.

We constructed the survey through an iterative process of item generation and refinement, followed by an assessment of the emerging survey's clarity and content validity by six independent doctoral students with expert knowledge of the ICF. Further refinements were made to the survey as per the reviewers' recommendations, and it was subsequently pilot tested on a small sample $(N=35)$ of senior medical students. This pilot version of the survey confirmed that it was easy to understand and comprehensive, time-efficient, and overall, that its completion presented low burden to the respondents.

Results from the pilot survey were further presented to graduate students and faculty members in an ICF-based graduate seminar for additional feedback and input. Overall, the survey was well received by this group, and further suggestions were adopted to improve the design and clarity of the survey. A final round of revisions resulted in the current survey, which can be found in the Appendix. We believe that this survey has high degrees of both face and content validity.

\section{Description of the survey}

The final survey (see Appendix) contained 17 items, 14 that used a $100 \mathrm{~mm}$ visual analogue scale (VAS) for participant responses. The remaining three items required a yes/no response from the participant. In the health-related literature, the VAS is commonly used in instruments that measure unidimensional constructs [55-58]; therefore, a VAS was adopted in order to address the core concepts associated with disability in the present context. Moreover, the use of a VAS provided respondents with the opportunity to reflect on their beliefs about disability and to answer where they felt their perceptions fit best along the entire VAS continuum. In trying to capture how the respondents perceived and conceptualized disability, the survey contained both "theory-based" statements and "scenario-based" contextual situations. The statements "Strongly Disagree" and "Strongly Agree" anchored each VAS, and participants were instructed to mark the scale at the point that they believed accurately represented their level of agreement for each item. For the theory-based questions, participants were asked to what extent they agreed with particular statements related to disability. For the scenario-based items, participants were asked to indicate to what extent they believed the described individual experienced a disability as defined by the ICF. A breakdown of survey questions and their associated constructs is presented in Table 3 .

\section{Data collection and analysis}

In agreement with the ethical approval for this study, and after obtaining formal permission from the target school of medicine, the authors approached students as part of a regular class meeting, provided a letter of information concerning the study, and distributed the questionnaire at that time. This meeting differed from 
166

How Medical Students Conceptualize Health and Disability

Bechard, Day, Dufour, Dzioba, McCabe, Rasmussen, \& Doyle
Journal of Research in Interprofessional Practice and Education

Vol. 1.2

August, 2010
Table 3

\section{Breakdown of survey constructs and associated questions}

\begin{tabular}{|c|c|}
\hline Construct & $\begin{array}{l}\text { Number of Questions } \\
\text { Listed by Corresponding } \\
\text { Survey Question Number }\end{array}$ \\
\hline Nonlinearity & 1 \\
\hline Language (value ladenness) & 2 \\
\hline Universalism & 3 \\
\hline Environmental factors & 4 \\
\hline Biopsychosocial model of health & $5,7,13,14$ \\
\hline $\begin{array}{l}\text { Application questions } \\
\text { Biopsychosocial model of health } \\
\text { Participation component }\end{array}$ & $\begin{array}{c}8 \\
9,10,11\end{array}$ \\
\hline Language (across professions) & 12 \\
\hline $\begin{array}{l}\text { Previous introduction to ICF and } \\
\text { extent of knowledge }\end{array}$ & 15,16 \\
\hline
\end{tabular}

Note: Items 13, 15, and 17 are yes/no; \#17 is a demographic question the pilot test of the survey in that the entire class was targeted ( $N=131$ versus the 35 students included in the pilot survey). Surveys were administered in class by the authors; a number of students participated as well via teleconference from a remote campus where a faculty member distributed questionnaires and collected them upon completion.

To ensure consistent and reliable assessments of each participant's responses, one of the authors measured each survey using a standard metric ruler with all measurements made in millimetres $(\mathrm{mm})$ starting at the left anchor (i.e., Strongly Disagree equalled 0 and Strongly Agree equalled 100). Responses were transformed into a score for each item and

items were averaged across all respondents. In addition to analyzing how the entire sample conceptualized disability (frequency distributions), $t$-tests were performed to determine if there were differences in the conceptualization of disability between those respondents who had been previously introduced to the ICF and those who had not. Because the data analysis process included 12 independent $t$-tests, the sequential Bonferroni correction [59] was employed. All statistical analyses were conducted using the statistical software SPSS (SPSS Inc., Chicago, IL).

\section{Results}

In total, 82 surveys were returned (62\% response rate). Respondents included 50 females, 27 males, and 5 reported no gender. Forty individuals (49\%) indicated that they had previous knowledge of the ICF (i.e., from education before medical school or their own reading). Twenty-three respondents indicated that they had completed the pilot version of our survey (66\% of pilot sample). We do not believe that those who completed the pilot version would have necessarily learned anything specific about the ICF framework as a result of their exposure to the earlier survey; therefore, it was not anticipated that prior exposure would alter responses on the revised version of the survey. The mean scores for all survey items are presented in Figure 2. For those questions based on statements about disability, respondents answered in a consistent fashion, whereby the means indicated a tendency to respond in a biopsychosocial manner. For Questions 2 through 6, respondents were asked to what extent they agreed with statements that are consistent with biopsychosocial concepts of disability. The resulting range of mean scores (86.7 to 90.1) indicated a higher percent agreement, reflecting a stronger relationship to the biopsychosocial perspective. For 
167

How Medical Students Conceptualize Health and Disability

Bechard, Day, Dufour, Dzioba, McCabe, Rasmussen, \& Doyle

Journal of Research in Interprofessional Practice and Education

Vol. 1.2

August, 2010 these items, higher scores represent greater agreement with a holistic concept of health and disability. Conversely, Questions 1 and 7 were negatively coded and queried the extent to which respondents agreed with concepts underlying biomedical appraisals of disability. Mean scores of 12.6 and 43.2, respectively, reflected disagreement with the biomedical-style statements, indicating an increased alignment with a biopsychosocial perspective.

Unlike the theory-based questions (items 1-7, 12), which measured percent agreement with statements about disability, Questions 8, 9, 10 and 11 required participants to assess a particular clinical scenario. These items yielded responses closer to the midpoint of the VAS and with greater variation in participant responses. For example, items 8 and 10 exhibited ranges of 17-100 and 13-100, respectively, and means of $62.7(\mathrm{SD}=21.9)$ and $63.9(\mathrm{SD}=22.4)$, respectively.

In addition to the general trends that were observed in how senior medical students appraised disability, data analyses also included exploring differences between mean scores for individuals who reported previous knowledge of the ICF and those who did not (Question 15). To determine whether or not statistically significant differences existed between these two groups, $t$-tests with a sequential Bonferroni correction [59] were conducted. After applying this correction, the alpha level was reduced from 0.05 to 0.0042 , and consequently, none of the observed differences between those who had previous knowledge of the ICF and those who did not, reached statistical significance. As such, the data were observed at face value to identify if trends appeared to exist in the data. The means for Questions 2 through 6 ranged from 81.9 to 86.4 for those individuals who did not have previous exposure to the ICF, and 90.9 to 94.0 for those individuals who did have knowledge of the ICF. Thus, although both those with and without previous knowledge of the ICF exhibited a tendency to view disability in a biopsychosocial fashion, individuals who were exposed to the ICF had consistently higher mean scores on items 2 through 6 . Likewise on the negatively coded questions (Questions 1 and 7), mean responses (9.6 and 38.3, respectively) for those with a previous introduction to the ICF were markedly lower, or more biopsychosocially oriented, compared to students who did not have a previous introduction to the ICF (means of 14.5 and 47.2, respectively).

Questions 8 through 11 were scenario-based questions that addressed the participation component of disability. Mean scores of students' responses did not indicate a definitive pattern. For Questions 8 and 9, mean scores for individuals who had prior exposure to the ICF were higher (66.6 and 58.6, respectively) relative to the mean scores of students who were not familiar with the ICF (58.9 and 49.0, respectively). Conversely, for Questions 10 and 11, mean percent agreement scores for those individuals who had knowledge of the ICF were lower (58.1 and 46.5, respectively) than the mean scores of individuals who did not have prior knowledge of the model (69.8 and 54.6, respectively). In addition, responses on Questions 8 through 11 exhibited large standard deviations, ranging from 21.4 to 30.3 for students who were exposed to the ICF and from 19.7 to 23.7 for individuals who did not have prior exposure. Finally, Question 14 surveyed the degree of familiarity that students had with the biopsychosocial model; the mean score for those individuals who had 
168

How Medical Students Conceptualize Health and Disability

Bechard, Day, Dufour, Dzioba, McCabe, Rasmussen, \& Doyle
Journal of Research in Interprofessional Practice and Education

Vol. 1.2

August, 2010 prior exposure to the ICF was higher (80.6) when compared with the mean score of individuals who were unfamiliar with the framework (56.7).

Figure 2

$$
\text { Mean survey scores }(n=82)
$$

Mean scores for all items

100

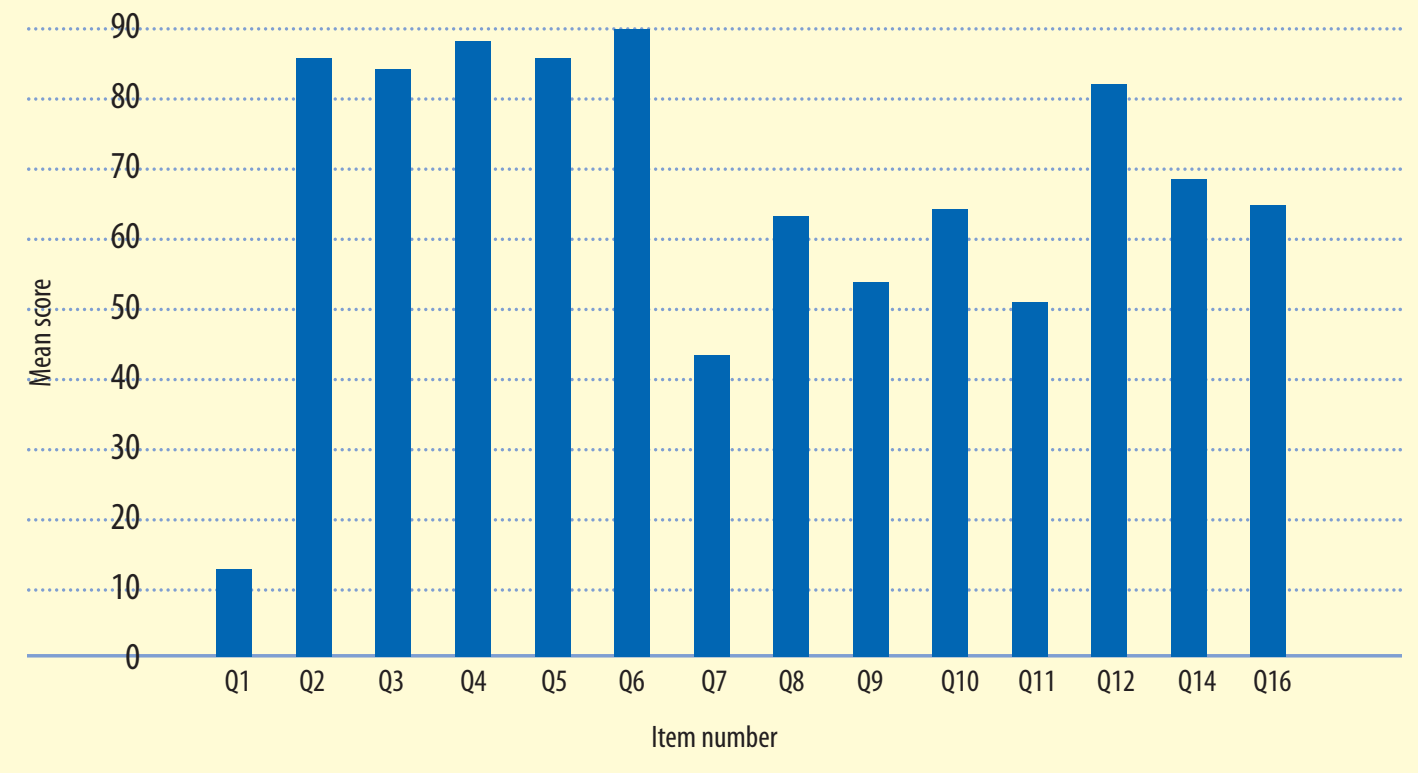

\section{Discussion}

This study explored how medical students at a Canadian university conceptualize health and disability. Specifically, we sought to explore how language and context were interpreted in these students' conceptualizations of disability, and whether their conceptualizations were oriented from within a biomedical or biopsychosocial perspective relative to the ICF. Because existing survey tools had not been identified from the literature, we constructed a survey specifically for the present study. This survey was designed to be valid, understandable, easy to complete, and of low burden; in its current form, the survey requires less than 15 minutes to complete. Further, we believe that the survey represents a high degree of strength and content validity.

Based on data gathered, these senior medical students generally tended to view health and disability using a biopsychosocial perspective. Interestingly though, mean response values for scenario-based questions were comparably lower (i.e., less biopsychosocially oriented) relative to theory-based questions. The somewhat contradictory nature of these results might imply that in an applied context, these medical students are less sensitive to the influence of one's social environment on health and functioning and the implications for experiencing disability. Further, if medical students have a more restricted view of disability in applied contexts, this may point 
169

How Medical Students Conceptualize Health and Disability

Bechard, Day, Dufour, Dzioba, McCabe, Rasmussen, \& Doyle
Journal of Research in Interprofessional Practice and Education

Vol. 1.2

August, 2010 to a potential stumbling block where interprofessional practice is concerned. However, our findings may also illustrate a mismatch in one's general awareness of issues and the practical application of such knowledge. More specifically, finding that an awareness exists, but is not directly translated to clinical scenarios may demonstrate that the educational model or methods of instruction potentially restrict such application. Because the biomedical model has been longstanding and dominant in medical education, its remnants within the clinical environment may restrict alternative approaches related to how a problem is approached. Arguably, a more holistic perspective of the patient's condition and the recognized value of the different participant professionals required would be desired in an interprofessional context. Stange and Ferrer recently warned that even for renewal efforts within primary healthcare, the focus on change in the disease and not people (and their communities) will have adverse consequences [60]. These authors contend that our current system undervalues care at the level of the whole person and community, resulting in a lost opportunity regarding healthcare renewal. We acknowledge these insights and suggest that as a foundational means for which to conceptualize health and disability, the ICF framework is optimal for the contemporary practice and education of healthcare professionals.

Although statistical analysis yielded no significant differences between individuals who had previous knowledge of the ICF when compared to those without, consistent trends were noted. Specifically, mean response scores of those who were familiar with the ICF reflected more biopsychosocial conceptualizations of disability relative to their colleagues who were not familiar with the ICF. These results demonstrate that those with previous knowledge of the ICF conceptualized disability from an increasingly biopsychosocial perspective and, therefore, a more contemporary framework. This finding is not surprising since one would expect that exposure to a framework that embodies a multidimensional view of health and embraces the values of the biopsychosocial model would result in increased awareness and integration of such concepts. Overall, exposure to the ICF framework and its inherent biopsychosocial structure may thus serve to facilitate interprofessional practice. We advocate for further research to explore the role of the ICF in successful interdisciplinary collaboration.

\section{Strengths and limitations}

One limitation to the present study was that a previously constructed questionnaire with demonstrated psychometric properties did not exist for use in exploring conceptualizations of disability. As such, we undertook the development of a survey that would permit us to investigate the nature of one's conceptualizations of disability. During this process, we were cognizant of seeking to base items solely on established constructs and language of the ICF framework. While we were careful and systematic to construct what we believed was a rigorous instrument, the original purpose of this work was directed toward assessing how medical students conceptualize disability. Originally conceived as a graduate course project, full psychometric testing was not the sole focus of the survey's development, nor did 
170

How Medical Students Conceptualize Health and Disability

Bechard, Day, Dufour, Dzioba, McCabe, Rasmussen, \& Doyle
Journal of Research in Interprofessional Practice and Education

Vol. 1.2

August, 2010 time and resource limitations permit such an endeavour. As such, we were conscious of interpreting the survey data descriptively and not subjugating the data to elaborate statistical tests. The authors remain committed to further development of the survey, with future plans to appropriately investigate the survey's psychometric properties.

Another limitation to this study was that our focus was uni-professional. The decision to focus solely on medical students at the time was guided by the fact that medicine represents one of the largest health disciplines, and that there is no discussion of the ICF framework in clinical use or education in the general medical literature. As noted previously, other health-related professions have actively contributed to the development and discourse of the ICF, have advocated for its use in clinical practice and research, and have begun to formally endorse the ICF in their scopes of practice. Therefore, given that interdisciplinary care teams will arguably always include a physician, we felt that it was pertinent to explore how the basic constructs and language of the ICF would be reflected in these medical students' conceptualizations of disability. We are now planning future investigations that will compare conceptualizations of disability across health-related disciplines and institutions that will explore implications to interdisciplinary education.

The difficulty of interpreting differences and inconsistencies between theory and scenario-based questions in this study sample remains an issue that requires further investigation. The response differences could relate to the impact of the complexity of real-life scenarios on medical students' perceptions of disability. Likewise, these inconsistencies might represent a barrier to knowledge translation of new evidence into practice. Such a barrier could be attributed to contemporary models and the language, which may be incongruent with current practice(s) and/or educational experience(s). This may be influenced further if such conceptualizations are generally unsupported in a given discipline's education, training, and relevant literature. While it was not the purpose of this study to explore these issues, these possibilities are recognized as pertinent to future investigations; therefore we simply provided possible interpretations based on this perspective.

Finally, because of the nature of performing multiple $t$-tests in statistical analyses of these data, overly conservative correction techniques [59] were ultimately employed and, at least in part, may have inhibited the ability to detect significant differences in the results. Yet the sample evaluated $(N=82)$ is not insubstantial, and the data gathered do provide a reasonable basis for preliminary observations. Therefore, it is hoped that more sophisticated comparison techniques will be possible to detect any emerging differences as we continue this line of inquiry.

\section{Implications for interprofessional education}

The ICF framework represents an advanced research and clinical framework for human health and disability. It embodies contemporary conceptualizations of health and disability and establishes a common, standard language for use in myriad healthrelated contexts. Further, this framework offers an advantageous tool for interprofessional education and training. For example, Broers, Poth, and Medves [61] solicited 
171

How Medical Students Conceptualize Health and Disability

Bechard, Day, Dufour, Dzioba, McCabe, Rasmussen, \& Doyle

Journal of Research in Interprofessional Practice and Education

Vol. 1.2

August, 2010 first-year students in medicine, nursing, occupational therapy, and physical therapy to define "interprofessional collaboration." These authors noted that while the four groups commonly reflected that interprofessional collaboration meant different professionals coming together to achieve better care for an individual, some interesting differences emerged, particularly relative to vocabulary. For example, Broers et al. noted that nursing and medical students referred to individuals receiving care as "patients," while occupational therapy and physical therapy students used the word "client." While such a difference in lexicon may appear to be relatively benign, every term carries with it its own connotations and highlights how even simple language differs across professions. Interestingly, Broers et al. reported that "communication" also emerged from participant responses as important in interprofessional collaboration. These authors did not discuss the ICF's potential to facilitate interprofessional education and collaboration; however, this finding is particularly pertinent because the ICF framework and standardized language could be adopted as the common model to facilitate the development of their program.

Another important finding to emerge from the Broers et al. study [61] was that "problem solving" was observed as a theme from the medical students' descriptions of interprofessional collaboration. While these authors did not discuss the ICF framework as a possible model to facilitate interprofessional education, the ICF framework has been recognized for its strength in fostering clinical reasoning and defining member roles in interprofessional teams [16]. Consequently, the ICF framework may provide an acceptable means of linking those from varied professional backgrounds in efforts to optimize problem solving in healthcare.

As a framework for human health, the ICF imparts a comprehensive, systematic, and common language that allows knowledge to be generated and transferred amongst healthcare providers, researchers, and policy makers. Further, the ICF has evolved to employ neutral language, emphasize health (rather than disease) and considers the whole person in one's experience of health and disability. It also provides a structured framework to guide both practice and research across all health professions. Overall, we argue that the ICF is the preferred framework for contemporary discourse about health and disability and holds the explicit potential for encouraging an "interprofessional mindset." We advocate that even basic exposure to the ICF could provide a good starting point in the education of health professionals; however, we acknowledge this goal needs to be fostered alongside practical education experiences that will facilitate the translation of the concepts inherent in the ICF into common practice $[51,52,54,62]$. Further research is needed to explore this translation into clinical practice and interprofessional collaboration. Overall, the ICF supports adoption of a common philosophy among different professional disciplines to facilitate the development of shared objectives and goals leading to improved interprofessional collaboration $[11,34,41]$, encouraging a needed restructuring of the general approach to healthcare to include the long neglected contextual factors that influence one's experience of health and disability. This requires a more diverse team of professionals to attend to the various domains of health that have been acknowledged to contribute to one's overall quality of care. 
172

How Medical Students Conceptualize Health and Disability

Bechard, Day, Dufour, Dzioba, McCabe, Rasmussen, \& Doyle
Journal of Research in Interprofessional Practice and Education

Vol. 1.2

August, 2010

\section{Conclusion}

With its inception in 2001, the WHO's International Classification of Functioning, Disability and Health (ICF) is currently understood to represent the conceptual basis for the definition, measurement, and policy formulation for health and disability in the 21st century [4]. The survey developed for the present study was designed to reflect the foundational framework of the ICF and its commitment to universal and neutral language, as well as to consider each individual's experience of health as a function of the context in which they live. Overall, senior medical students in this study were generally found to conceptualize disability from a biopsychosocial orientation. This was more pronounced among students who were familiar with the ICF framework. Interestingly, a biopsychosocial orientation was not consistently maintained for applied questions (clinical scenarios). Our current healthcare climate requires that the common conceptualization of health moves beyond the singular biomedical perspective to a more holistic, biopsychosocial perspective. This is of particular importance as the shift towards team-based models of interprofessional care continues to gain momentum. Closing conceptual and language-based gaps relative to concepts of health and disability among all healthcare professionals is not only pertinent, but also essential to improving interprofessional collaboration and service provision. The ICF provides an advanced framework of health and a common language for all health professionals that supports interprofessional collaboration and education. Further examination of how the ICF is translated into practice and education is important as team-based models of care are increasingly advocated and continue to evolve.

\section{Acknowledgements}

The authors wish to acknowledge our student and faculty colleagues, past and present, from the Rehabilitation Sciences Graduate Seminar at the University of Western Ontario. We thank them for their continued feedback and support of our endeavour. We would also like to acknowledge the support of the Schulich School of Medicine and Dentistry at the University of Western Ontario. And, we thank our reviewers for their valuable comments that have strengthened our work.

\section{Note}

1. This article is a collaborative effort of all authors; however, the contributions of the first three authors should be considered primary and equal.

\section{References}

1. Bickenbach, J., Chatterji, S., \& Badley, E. (1999). Models of disablement, universalism and the International Classification of Impairments, disabilities and handicaps. Social Science and Medicine, 48(9), 1173-1187.

2. Bruyere, S., VanLooy, S., \& Peterson, D. (2005). The International Classification of Functioning Disability and Health: Contemporary literature overview. Rehabilitation Psychology, 50(2),113-121.

3. Jette, A.M. (2006). Toward a common language for function, disability and health. Physical Therapy, 86(5), 726-734.

4. World Health Organization. (2001). International classification of functioning, disability and health. Geneva: World Health Organization.

5. Engel, G. (1977). The need for a new medical model: A challenge for biomedicine. Science, 196(4286),129-136. 
173

How Medical Students Conceptualize Health and Disability

Bechard, Day, Dufour, Dzioba, McCabe, Rasmussen, \& Doyle

Journal of Research in Interprofessional Practice and Education

Vol. 1.2

August, 2010
6. Stephenson, R., \& Richardson, B. (2008). Building an interprofessional curriculum framework for health: A paradigm for health function. Advances in Health Sciences Education: Theory and Practice, 3(4), 547-557.

7. Heinen, M.M., van Achterberg, T., Roodbol, G., \& Frederiks, C.M. (2005). Applying ICF in nursing practice: classifying elements of nursing diagnoses. International Nursing Review, 52(4), 304-312.

8. Van Achterberg, T., Holleman, G., Heijnen-Kaales, Y., Van der Brug, Y., Roodbol, G., Stallinga, H.A., Hellema, F., \& Frederiks, C.M. (2005). Using a multidisciplinary classification in nursing: The International Classification of Functioning Disability and Health. Journal of Advanced Nursing, 49(4), 432-441.

9. Stewart, D. (2007). International Classification of Functioning, Disability and Health. Canadian Journal of Occupational Therapy, 74, 217-220.

10. Godges, J.J. \& Irrgang, J.J. (2008). ICF-based practice guidelines for common musculoskeletal conditions. Journal of Orthopaedic and Sports Physical Therapy, 38(4), 167-168.

11. Campbell, W. \& Skarakis-Doyle, E. (2007). School-aged children with SLI: the ICF and a framework for collaborative service delivery. Journal of Communication Disorders, 40(6), 513-535.

12. Eadie, T.L. (2003). The ICF: A proposed comprehensive framework for rehabilitation of individuals who use alaryngeal speech. American Journal of Speech-Language Pathology, 12(2), 189-197.

13. Threats, T. (2006). Towards an international framework for communication disorders: Use of the ICF. Journal of Communication Disorders, 39(4), 251-265.

14. Gilchrist, L.S., Galantino, M.L., Wampler, M., Marchese, V.G., Morris, G.S., \& Ness, K.K. (2009). A framework for assessment in oncology rehabilitation. Physical Therapy, 89(3), 286-306.

15. Penney, J., MacKay-Lyons, M.J., \& McDonald, A. (2007). Evidence-based stroke rehabilitation: Case analysis using the international classification of functioning, disability and health framework. Physiotherapy Canada, 59(1), 22-36.

16. Tempest, S. \& McIntyre, A. (2006). Using the ICF to clarify team roles and demonstrate clinical reasoning in stroke rehabilitation. Disability and Rehabilitation, 28(10), 663-667.

17. Bartlett, D.J., \& Lucy, D. (2004). A comprehensive approach to outcomes research in rehabilitation. Physiotherapy Canada, 56, 237-247.

18. Bartlett, D., \& Palisano, R. (2000). A multivariate model of determinants of motor change for children with cerebral palsy, Physical Therapy, 80(6), 598-614.

19. Hunt, M.A., Birmingham, T.B., Skarakis-Doyle, E., \& Vandervoort, A.A. (2008). Towards a biopsychosocial framework of osteoarthritis of the knee. Disability and Rehabilitation, 30(1), 54-61.

20. Palisano, R. (2006). A collaborative model of service delivery for children with movement disorders: A framework for evidenced-based decision making. Physical Therapy, 86(9), 1295-1305.

21. Rauch, A., Cieza, A., \& Stucki, G. (2008). How to apply the International Classification of Functioning, Disability and Health (ICF) for rehabilitation management in clinical practice. European Journal of Physical and Rehabilitation Medicine, 44(3), 329-342.

22. Schwarzkopf, S., Ewert, T., Dreinhöfer, K., Cieza, A., \& Stucki, G. (2008). Towards an ICF Core Set for chronic musculoskeletal conditions: Commonalities across ICF Core Sets for osteoarthritis, rheumatoid arthritis, osteoporosis, low back pain and chronic widespread pain. Clinical Rheumatology, 27(11), 1355-1361.

23. Stucki, A., Cieza, A., Michel, A., Stucki, G., Bentley, A., Culebras, A., Tufik, S., Kotchabhakdi, N., Tachibana, N., Usturn, B., \& Partinen, M. (2008). Developing ICF core sets for persons with sleep disorders based on the International Classification of Functioning, Disability and Health. Sleep Medicine, 9(2), 191-198.

24. Tschiesner, U., Ceiza, A., Rogers, S., Piccirillo, J., Funk, G., \& Stucki, G. (2007). Developing core sets for patients with head and neck cancer based on the International Classification of Functioning, Disability and Health (ICF). European Archives of Oto-Rhino-Laryngology, 264(10), 1215-1222.

25. Eliasson, A.C. (2005). Improving the use of the hands in daily activities: Aspects of the treatment of children with cerebral palsy. Physical \& Occupational Therapy in Pediatrics, 25(3), 37-60.

26. American Speech-Language-Hearing Association. (2004). Scope of practice in audiology_[Internet]. Rockville, MD: American Speech-Language-Hearing Association. URL: ihhttp://wwww.asha.orgi i/docs/html/SP2004-00192.htmili [December 2, 2009].

27. American Speech-Language-Hearing Association. (2004). Scope of practice in speech-language pathology. Rockville, MD: American Speech-Language-Hearing Association. URL: !http:/_www_asha_org/docs/html/SP2007-00283.htmli [December 2, 2009]. 
174

How Medical Students Conceptualize Health and Disability

Bechard, Day, Dufour, Dzioba, McCabe, Rasmussen, \& Doyle

Journal of Research in Interprofessional Practice and Education

Vol. 1.2

August, 2010
28. American Physical Therapy Association. (2008). APTA endorses World Health Organization ICF model [Internet]. Alexandria, VA: American Physical Therapy Association. URL: thttp://www.apta.org/AM/Template.cfm?Section=Home\&TEMPLATE=/CM/ContentDisplay. 'cfm\&QONTENTID=50081] [December 2, 2009].

29. Nüchtern, E., \& Mohrmann, M. (2006). Why does evidence-based medicine need the international classification of functioning disability and health [abstract]? Medizinische Klinik (Munich), 101(1), 9-14.

30. Institute of Medicine. (2007). The future of Disability in America. Washington, DC: National Academy Press.

31. Canadian Institute for Health Information. (2005). International Classification of Functioning, Disability and Health [Internet]. Ottawa: Canadian Institute for Health Information. URL:

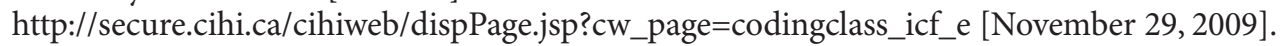

32. Mueller, M., Boldt, C., Grill, E., Strobl, R., \& Stucki, G. (2008). Identification of ICF categories relevant for nursing in the situation of acute and early post-acute rehabilitation. BMC Nursing, 7, 3.

33. Allan, C.M., Campbell, W.N., Guptill, C.A., Stephenson, F.F., \& Campbell, K.E. (2006). A conceptual model for interprofessional education: The international classification of functioning, disability and health (ICF). Journal of Interprofessional Care, 20(3), 235-245.

34. Dufour, S., \& Lucy, S. (2010). Situating primary health care within the International Classification of Functioning, Disability and Health: Enabling interprofessional collaboration. Journal of Interprofessional Care, (Early Online), 1-12.

35. Clark, P., Cott, C., \& Drinka, T. (2007). Theory and practice in interprofessional ethics: A framework for understanding ethical issues in health care teams. Journal of Interprofessional Care, 21(6), 591-603.

36. Orchard, C., Curran, V., \& Kabene, S. (2005). Creating a culture for interdisciplinary collaborative professional practice. Medical Education Online, 10(11),1-13. URL: htttp://_www. 'online.org/volume 10.htmin' [June 15, 2009].

37. Shaw, L, \& Mackinnon, J. (2004). A multi-dimensional view of health. Education for Health, 17(2), 213-222.

38. Stewart, M., Brown, J.B., Harris, S., \& Reid, G. (2003). Teamwork and teambuilding: A report to the Ontario Family Health Network, Ontario Ministry of Health and Long-Term Care. London, ON: Centre for Studies in Family Medicine and The College of Family Physicians of Canada. Funded by the Ministry of Health of Ontario and Long-Term Care. URL:

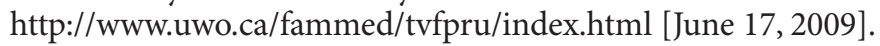

39. Badley, E. (1995). The genesis of handicap: Definitions, models of disablement, and role of external factors. Disability and Rehabilitation, 17(2), 53-62.

40. Thuriaux, M.C. (1995). The ICIDH: Evolution, status and prospects. Disability and Rehabilitation, 17(3-4), 112-118.

41 Armstrong, P. (2006). Advancing interdisciplinary health research: A synergism not to be denied. Canadian Medical Association Journal, 175(7), 761.

42. Nolte, J., \& Tremblay, M. (2005). Enhancing interdisciplinary collaboration in primary health care in Canada. Ottawa: Enhancing Interdisciplinary Collaboration in Primary Health Care

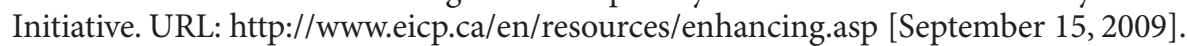

43. Interprofessional Care Steering Committee. (2007). Interprofessional care: A blueprint for action in Ontario. Toronto: Health Force Ontario. URL: http://www. healthforceontario.cal [/What I-

44. Payne, M. (2000). Teamwork in multiprofessional care. London: MacMillan Press.

45. Pringle, D., Levitt, C., Hosbrugh, M., Wilson, R., \& Whittaker, M. (2000). Interdisciplinary collaboration and primary health care reform. Canadian Family Physician, 46, 763-765.

46. Schoen, C., Osborn, R., Phuong, T.H., Doty, M., Peugh, J., \& Zapert, K. (2006). On the front lines of care: Primary care doctors' office systems, experiences, and views in seven countries. Health Affairs, 25(6), w555-571.

47. Grumbach, K., \& Bodenheimer, T. (2004). Can health care teams improve primary care practice? Journal of the American Medical Association, 291(10), 1246-1251.

48. Lemieux-Charles, L., \& McGuire, W. (2006). What do we know about health care team effectiveness? A review of the literature. Medical Care Research and Review, 63(3), 263-300.

49. Ingersoll, G., \& Shmitt, M. (2003). Interdisciplinary collaboration, team functioning, and patient safety. Rochester: University of Rochester Medical Centre.

50. Hall, P. (2005). Interprofessional teamwork: Professional cultures as barriers. Journal of Interprofessional Care, S1, 188-196. 
175

How Medical Students Conceptualize Health and

Disability

Bechard, Day, Dufour, Dzioba, McCabe, Rasmussen, \& Doyle
51. Duckett, S. (2009). Interdependence of health and education sectors in meeting health human resource needs. Healthcare Papers, 9(2), 30-34.

52. Soklaridis, S., Oandasan, I., \& Kimpton, S. (2007). Family health teams: Can health professionals work together? Canadian Family Physician, 53(7), 1198-1199.

53. Health Canada. Interprofessional education for collaborative patient-centered practice. (1 October,

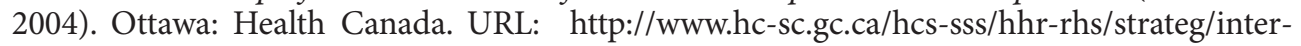
proflindex-eng.phpi [

54. Eisler, G. (2009). Healthcare provider education: From institutional boxes to dynamic networks. Healthcare Papers, 9(2), 45-52.

55. Takemura, Y., Liu, J., Atsumi, R., \& Tsuada, T. (2006). Development of a questionnaire to evaluate patient satisfaction with medical encounters. The Tohoku Journal of Experimental Medicine, 210(4), 273-281.

56. König, H.H., Roick, C., \& Angermeyer, M.C. (2007). Validity of the EQ-5D in assessing and valuing health status in patients with schizophrenic, schizotypal or delusional disorders. European Psychiatry, 22(3), 177-187.

57. Portney, L.G., \& Watkins, M.P. (2000). Foundations of clinical research: Foundations to practice, 2nd ed. Upper Saddle River, NJ: Prentice Hall Health.

58. Sayers, M.S., \& Newton, J.T. (2006). Patients' expectations of orthodontic treatment: Part 1 development of a questionnaire. Journal of Orthodontics, 33(4), 258-269.

59. Rice, W.R. (1989). Analyzing tables of statistical tests. Evolution, 43(1), 223-225.

60. Stange, K., \& Ferrer, R. (2009). The paradox of primary care. Annals of Family Medicine, 7(4), 293-299.

61. Broers, T., Poth, C., \& Medves J. (2009). What's in a word? Understanding “interprofessional collaboration" from the students' perspective. Journal of Research in Interprofessional Practice and Education, 1(1), 3-9. URL:'ihttp://jripe.org/index.php/journal/article/view/1/13i'[December 3, 2009].

62. Hind, M., Norman, I., Copper, S., Gill, E., Hilton, R., Judd, P., \& Jones, S. (2003). Interprofessional perceptions of health care students. Journal of Interprofessional Care, 17(1), 21-34. 
176

How Medical Students Conceptualize Health and Disability

Bechard, Day, Dufour, Dzioba, McCabe, Rasmussen, \& Doyle
Journal of Research in Interprofessional Practice and Education

\section{Appendix}

\section{Sample survey questions}

The following survey contains two types of questions: theory based and application based questions. The theory based questions address various concepts related to disability, whereas the application questions focus on the respondent's perception of disability in different clinical situations. Instructions for each type of question are provided within the body of the survey. Please read all instructions for each question carefully and mark the scale below each question only once. This survey consists of 17 questions and should take less than 15 minutes to complete.

When marking the scale, please do so with a SINGLE VERTICAL LINE, NOT with a circle or an $\mathrm{X}$, as demonstrated below.

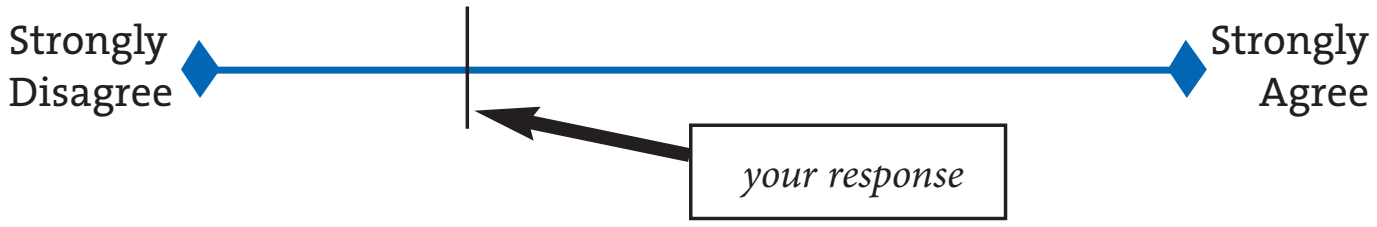

Before you begin, please read the definition of "disease/health condition" as it is used in this survey:

The term "disease/health condition" should be interpreted as broadly as possible. It should be taken to mean any ill-health resulting from, but not limited to, effects resulting from diseases and pathogens (e.g., cancer and influenza), musculoskeletal injuries (e.g., fractures and soft tissue injuries), as well as mental illnesses (e.g., depression, generalized anxiety disorder), and chronic disorders (e.g., diabetes, arthritis).

You may refer back to this definition at any time.

To what extent do you agree or disagree with the following statements:

1. A disease/health condition will always lead to a disability (an inability to perform a certain task or activity), and a disability will always lead to a handicap (the inability to participate in a social setting or social environment).

\section{Strongly}

Disagree

Strongly

Agree

2. There is a difference between a "disability" and a "handicap." Strongly Disagree

Strongly

Agree

3. Disability is a continuous concept (i.e., one's health status may improve or decline over time) and people may experience varying degrees of disability across their lifespan.
Strongly Disagree
Strongly

Agree 


\section{JRIPE}

177

How Medical

Students

Conceptualize

Health and

Disability

Bechard, Day, Dufour, Dzioba, McCabe, Rasmussen, \& Doyle
Journal of Research in Interprofessional Practice and Education

Vol. 1.2

August, 2010
Journal of Research in Interprofessional Practice and Education

4. An individual may be disabled in one environment (i.e., one's immediate surroundings), but not in another environment.

Strongly

Disagree Strongly Agree

5. Psychological (e.g., emotional status/changes) and/or social factors (e.g., one's family support, socio-economic status) and consequences should be considered when evaluating a disease/health condition.

\section{Strongly}

Disagree Strongly

Agree

6. One's ability to cope (i.e., deal effectively with something difficult) with a disease/health condition will impact the level of disability the person will experience.

\section{Strongly Disagree}

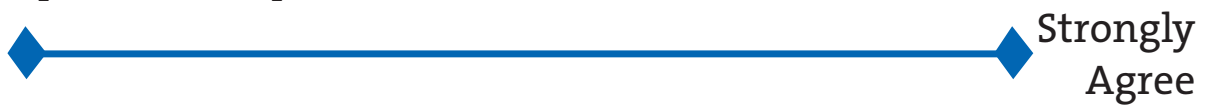

7. Successful treatment is primarily determined by ending the active process of the disease or pathogen in question.

Strongly Disagree

The next four questions pertain to a specific example. Please read the example and then follow the same instructions used before to mark your response on the scale.

8. After four consecutive visits, a forty-year old individual continues to complain of chronically reduced muscle power (strength). Following exhaustive medical testing, there is no conclusive evidence as to the presence or origin of these complaints. To what extent do you agree or disagree that this individual may be disabled?

\section{Strongly Disagree}

\section{Strongly}

Agree

9. An individual who enjoys playing golf recreationally experiences an acute loss of shoulder range of motion. This limitation only affects their golf swing and does not affect any of their other daily functions. To what extent do you agree or disagree that this individual is disabled?

\section{Strongly} Disagree Strongly Agree

10. An individual has completely recovered from an acute psychotic episode. To what extent do you agree or disagree that this individual may still experience problems participating in social situations?

Strongly Disagree Strongly Agree 


\section{JRIPE}

178

How Medical Students Conceptualize Health and

Disability

Bechard, Day, Dufour, Dzioba, McCabe, Rasmussen, \& Doyle
Journal of Research in Interprofessional Practice and Education

Vol. 1.2

August, 2010
Journal of Research in Interprofessional Practice and Education

11. Ten years following successful treatment for an episode of an acute mental illness (e.g., post-partum depression), an individual is in a state of good health. To what extent do you agree or disagree that this individual may still experience problems participating in social situations involving those who are aware of their previous diagnosis?

Strongly

Disagree

Strongly

Agree

For the next six items, please follow the directions provided in the question and answer on the scale provided.

12. To what extent do you agree or disagree that it is important to have a common language regarding health and disability among all health care providers (e.g., physicians, nurses, allied health professionals) independent of their discipline?

Strongly

Disagree Strongly Agree

13. Have you ever been introduced to the biopsychosocial model of health? Please circle your answer below. Yes No

14. If you answered no to \# 13 , please proceed to question \#15. If you answered yes, to what extent are you familiar with the biopsychosocial model of health?

Not at all familiar Very Familiar

15. Have you ever been introduced to the World Health Organization's International Classification of Functioning, Disability and Heath (ICF)? Please circle your response to this question below.

$$
\text { Yes No }
$$

16. If you answered no to \#15, please proceed to question \#17. If you answered yes, to what extent are you familiar with this framework?

Not at all familiar

17. Have you ever completed an earlier version (i.e., pilot version) of this survey? Please circle your answer below.

Yes No

This is the end of the survey. Thank you for your time and participation. Please return this survey to one of the investigators. 